\title{
Algorithm for estimating the mode and electricity losses in distribution electric networks 6-110 kV conditions of incomplete information
}

\author{
Madiyar Erejepov ${ }^{1}$, Novikov A N², B M Khusanov ${ }^{2}$, Bayram Seytmuratov $^{1}$, Ziynatdin Sayimbetov $^{1}$ \\ ${ }^{1}$ Karakalpak State University \\ ${ }^{2}$ Joint Stock Company "Scientific and Technical Center of the Federal Grid Company of the Unified Energy System", Russia
}

\begin{abstract}
The article provides an analysis of methods for calculating electricity losses. The conditions for the application of methods for calculating electricity losses are determined, and structural separated losses in electrical networks are shown. An algorithm for calculating electricity losses is presented, which makes it possible to obtain acceptable results with a minimum of initial information, which has a limited degree of reliability.
\end{abstract}

Key words. Participation factor and power factor, time of maximum losses.

\section{Introduction}

When performing calculations of the steady state and energy losses in distribution networks of 6-110 kV, we are faced with a lack of circuit and mode information. At the same time, to perform calculations, it is possible to use methods that allow taking into account the features of the information support of networks of this class [1-7].

This approach is implemented in the DelPROD program, which makes it possible to calculate the mode and energy losses in open distribution networks of 6-10 kV and 35-110 $\mathrm{kV}$, taking into account the incompleteness of information.

The program is designed to assess the mode and energy losses in open distribution networks 6-110 kV with uncertainty in the initial data.

The program provides:

-input, creation and correction of the base of initial data on the schemes of distribution networks;

-input and correction of initial data on feeder loads;

-import of data from text files into databases;

-determination of the total characteristics of the substation;

-calculation and formation of the feeder equivalent circuit;

-evaluation of the state of the feeder mode;

-calculation of steady-state modes of distribution networks;

-calculation of electricity losses;

-drawing up a balance of electricity for feeders;

-display of calculation results.

Sources of information for calculating the mode and EE losses of an open distribution network are: network diagram, seasonal (monthly) measurements at $35-110 \mathrm{kV}$ supply substations, data on the monthly position of switching devices in the network [8-12].

The algorithm is designed to evaluate the modes of open networks, taking into account the features of information support. The statement of the problem of assessing the state of the mode is formulated as the problem of determining the calculated loads of nodes using the available incomplete information and to the maximum extent corresponding to the most reliable operational information about $\mathrm{R}_{\mathrm{GU}}, \mathrm{O}_{\mathrm{GU}}$ - active and reactive power and $\mathrm{U}_{\mathrm{GU}}$, - the voltage measured at the head section (GU) of open feeders RS departing from large substations.

Mode estimation is based on algorithms for iterative refinement of node loads and calculation of normal mode. The estimation process ends according to the condition of the minimum of the objective function, which is formed in the form:

$$
\Phi=\varepsilon_{R}\left(\mathrm{P}_{G U}-\mathrm{P}_{R G U}^{(i)}\right)^{2}+\varepsilon_{q}\left(Q_{G U}-Q_{R G U}^{(i)}\right)^{2}
$$

where $\mathrm{P}_{\mathrm{RGU}}{ }^{(\mathrm{i})}, \mathrm{Q}_{\mathrm{RGU}}{ }^{(\mathrm{i})}$ - PG powers, calculated in the iterative process and corresponding to the calculated values of loads and voltages at the nodes of the circuit;

$\varepsilon_{R}, \varepsilon_{q}$ - a priori weights that characterize the degree of confidence in the measurements, which are determined from the results of measuring the error variance $\sigma^{2}$

$$
\beth=\frac{1}{\sigma^{2}}
$$

To solve (1), an iterative procedure was developed for sequentially refining the loads of network nodes and calculating modes. The distribution of the loads of the nodes is carried out in proportion to the rated powers of the transformers in the nodes using the coefficients of participation and power, which are specified at each step of the iteration [15-19].

To calculate the voltages and powers at the head section when specifying loads in the nodes, a two-stage method was 
used.

The algorithm for distributing loads and calculating the mode consists of the following stages:

1) Determination of the initial values of the participation factors and power:

$$
\begin{gathered}
K_{y}=\frac{S_{G U}}{S_{\Sigma T R}} \\
\cos \varphi=\frac{\mathrm{P}_{G U}}{S_{G U}}
\end{gathered}
$$

where $\mathrm{S}_{\mathrm{GU}}$ - full power of the head section; $S_{\sum^{T R^{-}}}$ total installed capacity of RS transformers;

2) Calculation of the capacities subject to the initial distribution between load nodes:

$$
\begin{aligned}
& \mathrm{P}_{R G U}=\mathrm{P}_{G U}-\Delta \mathrm{P} \\
& Q_{R G U}=Q_{G U}-\Delta Q
\end{aligned}
$$

Where power losses are approximately

$$
\begin{aligned}
& \Delta \mathrm{P}=(6-10) \% \mathrm{P}_{G U} \\
& \Delta Q=(20-30) \% Q_{G U}
\end{aligned}
$$

on the power of the head section;

3) Determination of loads at nodes $j$ in accordance with the values of the coefficients of participation and power at the $i$-th iteration:

$$
\begin{aligned}
P_{j}^{(i)} & =S_{\text {TR.Ins }} \cos ^{(i)} K_{y}^{(i)} \\
Q_{J}^{(i)} & =\sqrt{\left(S_{\text {TR.Ins }} J K_{y}^{(i)}\right)^{2}-P_{i}^{(i) 2}}
\end{aligned}
$$

Where $P_{j}^{(i)}, Q_{J}^{(i)}$ - active and reactive power in $j-\mathrm{m}$ node; $S_{T R \text {.ins }} j$-installed power of the transformer in $j-\mathrm{m}$ node.

4) Calculation by a two-stage method of overflows and power losses along the branches of the circuit, as well as the voltage of nodes at given loads $P_{j}^{(i)}, Q_{J}^{(i)}$ in nodes. The calculation results are power flows, corresponding voltages and calculated values $\mathrm{P}_{R G U}^{(i)}, Q_{R G U}^{(i)}$ the capacities of the head section, determined at the $\mathrm{i}$-th iteration;

5) Checking condition (1). When the value of the function is less than the specified accuracy, the calculation ends. If the condition is not met, then go to step 6 to continue the calculation;

6) Clarification of participation factors and capacity in accordance with new calculated values $\mathrm{P}_{R G U}^{(i)}, Q_{R G U}^{(i)}$ :

$$
\begin{aligned}
& K_{y}^{(i+1)}=\frac{\frac{K_{y}^{1}}{S_{P}^{(1)}}}{S_{G U}} \\
& \cos ^{(i+1)}=\frac{\cos ^{1}+Q_{R G U}^{(i)}}{\gamma Q_{G U}}
\end{aligned}
$$

Where $\gamma=(1-100)-$ an empirically set coefficient that determines the step of updating the power factor of the loads;

7) Transfer of control to step 3 - continuation of the iterative calculation after specifying the coefficients $K_{u}$ and $\cos \varphi[20-25]$.

The algorithm also provides for the ability to take into account additional information, namely, information on loads in the form of a power setting $\mathrm{P}_{\mathrm{lj}}, \mathrm{Q}_{\mathrm{lj}}$, current measurements $\mathrm{I}_{\mathrm{zj}}, \cos \varphi$ and load factors of transformers $K_{\text {sh.c }}$, If the additional information of the nodal loads is specified in the form of power, then the unknown values of the loads of the nodes are also determined by the capacities of the head section $P_{G U}, Q_{G U}$ In this case, the known values of the powers of the load nodes are summed up $\sum P_{L J}, \quad \sum Q_{L J}(j=$ $1,2, \ldots, \mathrm{k}$ - the number of specified load nodes) and subtracted from the power of the head section. In accordance with this, the following changes are made to the algorithm:

1) Instead of calculation formulas (2.10), (2.11) the expression is used

$$
\begin{gathered}
K_{y}=\frac{\left(s_{G U}-\left(\sum s_{L J}\right)\right)}{\left(S_{\Sigma T P}-\sum s_{T P L J}\right)} \\
\cos \varphi=\frac{\left(P_{G U}-\sum P_{L J}\right)}{\left(S_{G U}-\sum S_{L J}\right)}
\end{gathered}
$$

Where $\sum S_{L J}-$ total apparent power of the given load nodes;

2) the power to be distributed initially is defined as

$$
\begin{aligned}
P_{R G U} & =\mathrm{P}_{G U}-\sum \mathrm{P}_{L}-\Delta \mathrm{P} \\
Q_{R G U} & =Q_{U E}-\sum Q_{L}-\Delta Q
\end{aligned}
$$

3) powers are determined only for those nodes where the values of loads are not specified according to ratios similar to (6), (7).

When specifying the currents of the nodes, at the i-th step of the iteration, the calculated values of the voltages are used to determine the powers of the nodes by the ratios []:

$$
\begin{aligned}
& S_{J}^{(i)}-\sqrt{3 U^{(i)} J, I_{J}^{(i)}}, \quad P_{J}^{(i)}=S_{J}^{(i)} \cos ^{(i)}, \\
& Q_{J}^{(i)}-\sqrt{S_{J^{2}}^{(i)}, I_{J}^{(i)}}
\end{aligned}
$$

where $S_{j}$ - full power $j$ - th node; $U_{j}$ - voltage $I_{j}$ - load current value $P_{j}$ - active power $Q_{j}$ - reactive power. If information about loads is specified in the form of an average load factor of load transformers Sh.c. then by expression

$$
I_{i}=\frac{S_{T P . I N S J}}{\sqrt{\left(3 U_{i}\right) \mathrm{K}_{\text {sh.c.J }}}}
$$



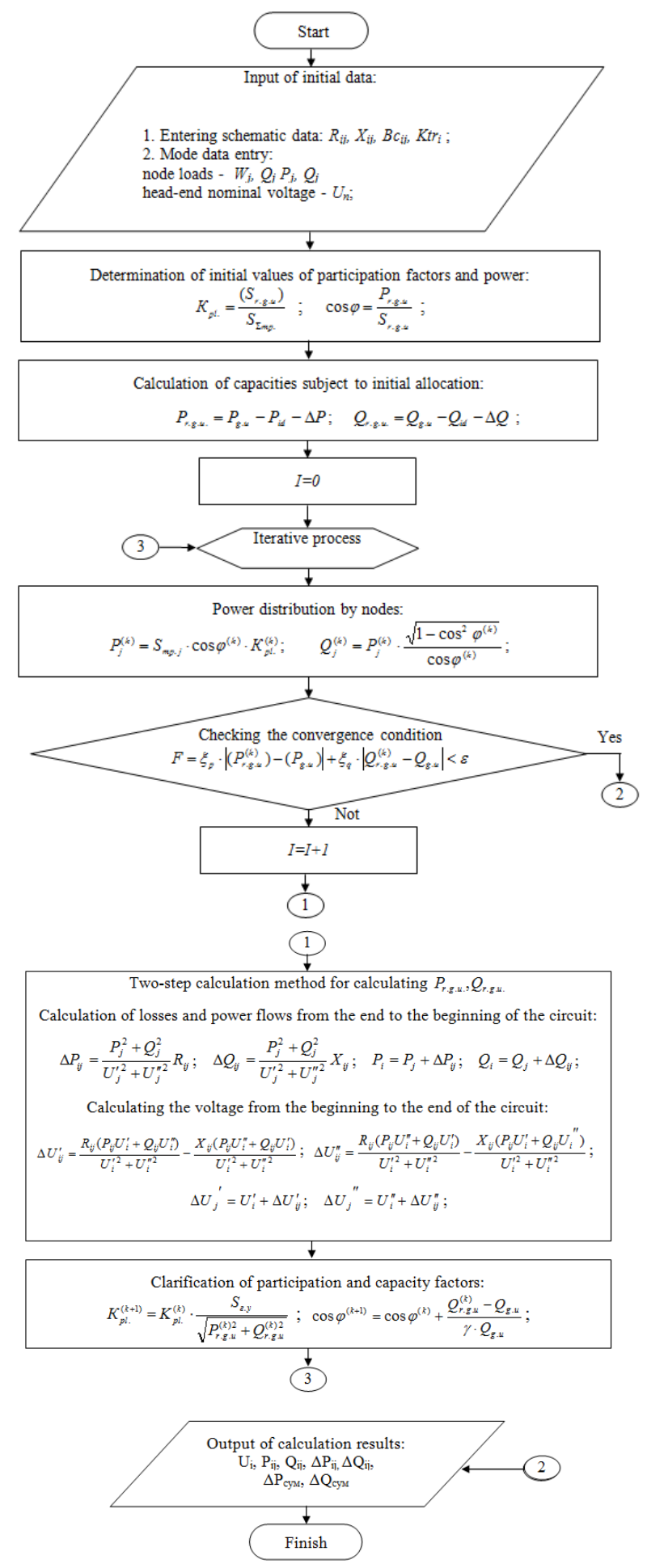

Fig. 1. Block diagram of the algorithm for calculating the SD RS.

The current in the $j$-th nodes is determined. Currents according to (15) are replaced by powers. After replacing the load currents with powers, the calculation is performed according to the algorithm with the given node loads described above;

4) in a two-stage calculation of the power of nodes with given loads, they are considered unchanged. The rest of the estimation algorithm is similar to that described [26-29].

It should be noted that in the calculations, the power factor $\cos \varphi$ for all load nodes is taken to be equal to the GI factor. If the nodes have additional information on $\cos \varphi$, then the given values are taken into account in the calculations in expression (12).

Basic formulas for calculations using the two-stage method:

Calculation of power flows from end to beginning for $i-j$ branches:

$$
\begin{aligned}
\Delta P_{i j} & =\frac{P_{j}^{2}+Q_{j}^{2}}{U_{j}^{\prime 2}+U_{j}^{\prime 2} R_{i j}} \\
\Delta Q_{i j} & =\frac{P_{j}^{2}+Q_{j}^{2}}{U_{j}^{\prime 2}+U_{j}^{\prime 2} X_{i j}}
\end{aligned}
$$

$P_{i}=P_{j}+\Delta P_{i j}, \quad Q_{i}=Q_{j}+\Delta Q_{i j}$

Calculation of stress from the beginning of the node to the end

$$
\begin{gathered}
\Delta U_{i j}^{\prime}=\frac{R_{i j}\left(U_{i j}^{\prime}+Q_{i j} U_{i}^{\prime \prime}\right)}{\left(U_{i}^{\prime 2}+U_{i}^{\prime \prime}\right)}-\frac{X_{i j}\left(P_{i j}^{\prime \prime}+Q_{i j} U_{i}^{\prime}\right)}{\left(U_{i}^{\prime 2}+U_{i}^{\prime \prime}\right)} \\
\Delta U_{i j}^{\prime}=\frac{R_{i j}\left(P_{i j}^{\prime \prime} U_{i}^{\prime \prime}+Q_{i j} U_{i}^{\prime}\right)}{\left(U_{i}^{\prime 2}+U_{i}^{\prime 2}\right)}+\frac{X_{i j}\left(P_{i j}^{\prime \prime} U_{i}^{\prime}+Q_{i j} U_{i}^{\prime}\right)}{\left(U_{i}^{\prime 2}+U_{i}^{\prime \prime}\right)} \\
U_{i}^{\prime}=U_{j}^{\prime}-\Delta U_{i j}^{\prime} \quad U_{j}^{\prime \prime}=U_{i}^{\prime \prime}-\Delta U_{i j}^{\prime \prime}
\end{gathered}
$$

The block diagram of the mode estimation algorithm taking into account the interval of the initial data is shown in Fig.1.

According to the results of the computational study, it became known that the developed algorithm allows obtaining acceptable results with a minimum of initial information, which has a limited degree of reliability [30-34].

This program can be used to determine the total losses of power and electricity in existing electrical networks, to analyze the modes and losses of electricity.

\section{References}

1. Baghaee, H.R.; Mirsalim, M.; Gharehpetian, G.B. Performance Improvement of Multi-DER Microgrid for Small- and Large-Signal Disturbances and Nonlinear Loads: Novel Complementary Control Loop and Fuzzy Controller in a Hierarchical Droop-Based Control Scheme. IEEE Syst. J. 2018, 12, 444-451.

2. Di Fazio, A.R.; Russo, M.; Valeri, S.; De Santis, M. Sensitivity-based model of low voltage distribution systems with distributed energy resources. Energies 2016, 9, 801.

3. Savier, J.S.; Das, D. Impact of network reconfiguration on loss allocation of radial distribution systems. IEEE Trans. Power Deliv. 2007, 22, 2473-2480.

4. Mahmoud, K.; Yorino, N.; Ahmed, A. Optimal Distributed Generation Allocation in Distribution Systems for Loss Minimization. IEEE Trans. Power Syst. 2016, 31, 960-969.

5. F.A.Hoshimov, I.I.Bakhadirov, M.S.Kurbanbayeva, N.A.Aytbayev. Development of specific standards of energy consumption by types of produced products of the spinning product // RSES 2020. E3S Web of Conferences. 216 (2020) 01169. https://doi.org/10.1051/e3sconf/202021601169

6. F.A.Hoshimov, I.I.Bakhadirov, A.A.Alimov, M.T.Erejepov. Forecasting the electric consumption of objects using artificial neural networks // E3S Web of $\begin{array}{llll}\text { Conferences. } & 216 & \text { (2020) } & 01170 .\end{array}$ https://doi.org/10.1051/e3sconf/202021601170 
7. I.U.Rakhmonov, A.N.Tovbaev, L.A.Nematov and T.Sh.Alibekova. Development of forecasted values of specific norms for the issues of produced products in industrial enterprises // ICMSIT-2020. Journal of Physics: Conference Series. 1515 (2020) 022050. doi:10.1088/17426596/1515/2/022050

8. I.U.Rakhmonov, F.A.Hoshimov. Development of an algorithm for evaluating the dominant factors that have the greatest impact on the energy intensity of products // ENERGY-21. E3S Web of Conferences. 209 (2020) 07018. https://doi.org/10.1051/e3sconf/202020907018

9. Usmanov E.G. Stability in a parallel resonant circuit with active load // RSES 2020. E3S Web of Conferences. 216 (2020) 01160. https://doi.org/10.1051/e3sconf/202021601160 10. Usmanov E.G., Khusanov B.M. Phase relations in resonant circuits with a wide falling section on the amplitude characteristic // RSES 2020. E3S Web of Conferences. 216 (2020) 01161. https://doi.org/10.1051/e3sconf/202021601161 11. I.U.Rakhmonov, K.M.Reymov and S.H.Dustova. Improvements in industrial energy rationing methods // MIP: Engineering-2020. E3S Web of Conferences. 862 (2020) 062070. doi:10.1088/1757-899X/862/6/062070

12. I.U.Rakhmonov, K.M.Reymov. Statistical models of renewable energy intermittency // RSES 2020. E3S Web of $\begin{array}{llll}\text { Conferences. } & 216 & \text { (2020) }\end{array}$ https://doi.org/10.1051/e3sconf/202021601167

13. I.U.Rakhmonov, N.N.Kurbonov. Analysis of automated software for monitoring energy consumption and efficiency of industrial enterprises // E3S Web of Conferences. 216 (2020) 01178. https://doi.org/10.1051/e3sconf/202021601178 14. F.A.Hoshimov, I.U.Rakhmonov, N.N.Niyozov. Technology to reduce energy costs in the electric steel melting shop // ENERGY-21. E3S Web of Conferences. 209 (2020) 07017. https://doi.org/10.1051/e3sconf/202020907017 15. K.M.Reymov, G.R.Rafikova, L.A.Nematov, Sh.Esemuratova. Existing condition and prospects of making power balance and managing load of electric consumers in uzbek power system // ENERGY-21. E3S Web of Conferences. $\quad 209 \quad 07015$. https://doi.org/10.1051/e3sconf/202020907015

16. A.D.Taslimov, F.M.Rakhimov, A.O.Norkulov, A.A.Yuldashev. Research of the optimum scale of standard sections of agricultural purpose lines // E3S Web of Conferences. $\quad 216 \quad 01158$. https://doi.org/10.1051/e3sconf/202021601158

17. A.D.Taslimov., M.V.Melikuziev, A.M.Najimova, A.A.Alimov. Economic load intervals for selection of cable sections for agricultural purpose // E3S Web of Conferences. $216 \quad$ (2020)

01159.

https://doi.org/10.1051/e3sconf/202021601159

18. Dmitriy Bystrov, Toirov Olimjon, Mustafakulova Gulzoda, Yakubova Dilfuza NISS2020: Proceedings of the 3rd International Conference on Networking, Information

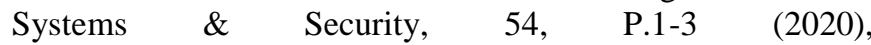
https://doi.org/10.1145/3386723.3387873

19. Dmitriy Bystrov, Toirov Olimjon, Giyasov Sanjar, Taniev Mirzokhid, Urokov Sardor NISS2020: Proceedings of the 3rd International Conference on Networking, Information Systems \& Security, 49, P. 1-4 (2020), https://doi.org/10.1145/3386723.3387868

20. Olimjon Toirov, Tulyagan Kamalov, Utkir Mirkhonov, Sardor Urokov, Dilnoza Jumaeva The mathematical model and a block diagram of a synchronous motor compressor unit with a system of automatic control of the excitation, E3S Web of Conferences, SUSE-2021 (2021) 21. Olimjon Toirov, Sardor Urokov, Utkir Mirkhonov, Hadha Afrisal, Dilnoza Jumaeva Experimental study of the control of operating modes of a plate feeder based on a frequency-controlled electric drive, E3S Web of Conferences, SUSE-2021 (2021)

22. Baratov B., Toshov J., Baynazov U. Method of calculating the gear ratios of the cones of tricone drill bits // E3S Web Conf., Volume 201, 01012, 2020, Ukrainian School of Mining $\quad$ Engineering - 2020. https://doi.org/10.1051/e3sconf/202020101012

23. Haqberdiev A., Toshov J. Analysis of the control system of electric motors of the running gear of self-propelled mine cars used in complex mining and technological conditions // E3S Web of Conferences 216, 01135 (2020), Rudenko International Conference "Methodological problems in reliability study of large energy systems" (RSES 2020), https://doi.org/10.1051/e3sconf/202021601135

24. K.M.Reymov, G.Turmanova, S.Makhmuthonov, B.Uzakov. Mathematical models and algorithms of optimal load management of electrical consumers // E3S Web of $\begin{array}{llll}\text { Conf. } & 216 & \text { (2020) }\end{array}$ https://doi.org/10.1051/e3sconf/202021601166

25. Yu.M.Bobozhonov, K.M.Reymov, B.T.Seytmuratov, T.Kh.Khakimov. Research of the dependence of the resistance of asynchronous generators with massive rotors on their design // RSES 2020. E3S Web of Conferences. 216 (2020) 01168. https://doi.org/10.1051/e3sconf/202021601168 26. A.N.Rasulov, M.R.Ruzinazarov, N.Toirova, T.Sh.Alibekova. Graphical-analytical method for constructing load characteristics // RSES 2020. E3S Web of Conferences. $\quad 216 \quad 01171$. https://doi.org/10.1051/e3sconf/202021601171

27. Rakhmonov I U, Nematov L A, Niyozov N N, Reymov K M and Yuldoshev T M 2020 Power consumption management from the positions of the general system theory Journal of Physics: Conference Series 1515 doi:10.1088/1742-6596/1515/2/022054

28. Karimov R.Ch., Bobojanov M.K., Rasulov A.N., Usmanov E.G. Controlled switching circuits based on nonlinear resistive elements (E3S Web of Conferences, 139, 01039, 2019), https://doi.org/10.1051/e3sconf/201913901039 29. Yu.Bobozhonov, B.Seytmuratov, B.Fayzullaev, A.Sultonov. Study of the influence of different designs of massive rotor of asynchronous generator on their maximum power // RSES 2020. E3S Web of Conferences. 216 (2020) 01177. https://doi.org/10.1051/e3sconf/202021601177 30. Taslimov A D, Rakhmonov I U 2019 Optimization of complex parameters of urban distribution electric networks Journal of Physics: Conference Series 1399 doi:10.1088/1742-6596/1399/5/055046

31. Rakhmonov I U, Niyozov N N 2019 Optimization setting of steel-smelting industry in the issue of alloy steels E3S Web Conf 139 doi:10.1051/e3sconf/201913901077

32. Rakhmonov I U, Reymov K M and Shayumova Z M 2019 The role information in power management tasks. E3S Web Conf 139 doi:10.1051/e3sconf/201913901080

33. Rakhmonov I U, Reymov K M 2019 Mathematical Models and Algorithms of Optimal Load Management of Electricity Consumers J ENERGETIKA. Proceedings of CIS 
higher education institutions and power engineering association 62(6) pp 528-535 doi:10.21122/1029-7448-201962-6-528-535

34. Rakhmonov I U, Tovbaev A N, Nematov L A and Alibekova T Sh 2020 Development of forecasted values of specific norms for the issues of produced products in industrial enterprises Journal of Physics: Conference Series 1515 doi:10.1088/1742-6596/1515/2/022050 